\begin{tabular}{l|lr|ll|ll} 
& ISRA (India) & $=\mathbf{1 . 3 4 4}$ & SIS (USA) & $=\mathbf{0 . 9 1 2}$ & ICV (Poland) & $\mathbf{6 . 6 3 0}$ \\
Impact Factor: & ISI (Dubai, UAE) $=\mathbf{0 . 8 2 9}$ & PUHЦ (Russia) $=\mathbf{0 . 2 0 7}$ & PIF (India) & $=\mathbf{1 . 9 4 0}$ \\
& GIF (Australia) & $\mathbf{0 . 5 6 4}$ & ESJI (KZ) & $\mathbf{4 . 1 0 2}$ & IBI (India) & $\mathbf{4 . 2 6 0}$ \\
& JIF & $\mathbf{1 . 5 0 0}$ & SJIF (Morocco) $=\mathbf{2 . 0 3 1}$ & & \\
\hline
\end{tabular}

\section{International Scientific Journal Theoretical \& Applied Science}

p-ISSN: 2308-4944 (print) e-ISSN: 2409-0085 (online)

Year: 2017 Issue: 12 Volume: 56

Published: $30.12 .2017 \quad$ http://T-Science.org
Gulvira Korkemova Azimkhanova lecturer of Propedeutics and Internal disease department International Kazakh-Turkish University by name Yassavi, Kazakhstan gulvira1202@mail.ru

Sarviniso Islamovna Ibragimova Master of medical science, lecturer of Propedeutics and Internal disease department International Kazakh-Turkish University by name

Yassavi, Kazakhstan sarvinsa@mail.ru

SECTION 20. Medicine.

arvinsa@mailin

\title{
THE FREQUENCY OF STOMACH CANCER AMONG MEN (LITERATURE REVIEW)
}

Abstract: The article presents a literature review of the prevalence of gastric cancer among men. The features of the frequency of occurrence of gastric cancer among men all over the world and in Kazakhstan, as well as some risk factors for the development of this disease, are considered.

Key words: stomach cancer, prevalence, men

Language: Russian

Citation: Azimkhanova GK, Ibragimova SI (2017) THE FREQUENCY OF STOMACH CANCER AMONG MEN. ISJ Theoretical \& Applied Science, 12 (56): 205-208.

Soi: http://s-o-i.org/1.1/TAS-12-56-32 Doi: crossef https://dx.doi.org/10.15863/TAS.2017.12.56.32

УДК 616.33.

\section{ЧАСТОТА ВСТРЕЧАЕМОСТИ РАКА ЖЕЛУДКА СРЕДИ МУЖЧИН (ОБЗОР ЛИТЕРАТУРНЫХ ДАННЫХ)}

Аннотация: В статье представлен литературный обзорраспространенности рака желудка среди мужчин. Рассмотрены особенности частоты встречаемости рака желудка среди мужчин во всем мире и в Казахстане а также некоторые факторы риска развития данного заболевания.

Ключевые слова: рак желудка, распространенность, мужчины

\section{Introduction}

Проблема онкологических заболеваний притягивает все большего внимания к себе в связи с неснижающим уровнем заболеваемости и смертности во всем мире. Рак желудка остается одним из самых распространенных заболеваний. Ежегодно регистрируется почти 800 тысяч новых случаев и 628 тысяч смертей от этого заболевания. Если данное заболевание наиболее часто встречается в таких странах как Япония,
Россия, Чили, Корея, Китай, Коста-Рика, Филиппины, тов США, Австралии, Новой Зеландии отмечается более низкие показатели по сравнению с другими странами [1].

\section{Materials and Methods}

По данным проекта Globocan Казахстан находится на 5-м месте по заболеваемости раком желудка среди мужчин.

Показатели заболеваемости раком желудка среди мужчин.

Таблица 1

\begin{tabular}{|l|l||l||}
\hline No & Страны & на $\mathbf{1 0 0 , 0 0 0}$ нас. \\
\hline 1 & Корея & 62.3 \\
\hline 2 & Монголия & 47.4 \\
\hline 3 & Япония & 45.7 \\
\hline
\end{tabular}




\begin{tabular}{|l|l|l||}
\hline № & Страны & на 100,000 нас. \\
\hline 4 & Киргизия & 35.7 \\
\hline 5 & Казахстан & 35.2 \\
\hline 6 & Китай & 32.8 \\
\hline 7 & Таджикистан & 30.1 \\
\hline 8 & Белоруссия & 29.1 \\
\hline 9 & Албания & 25.3 \\
\hline 10 & Россия & 24.5 \\
\hline \hline
\end{tabular}

[http://globocan.iarc.fr]

Среди стран бывшего СССР рак желудка находится на 1-ом месте у мужчин в Туркмении, Узбекистане и Киргизии (18,3-21,7\%). В России (у лиц обоего пола), Казахстане, Армении и Азербайджане (у мужчин) в структуре онкозаболеваемости рак желудка устойчиво занимает 2-е ранговое место. По сравнению с 1990 годом его доля снизилась в России, Казахстане, Армении и Таджикистане, увеличилась в таких странах как Киргизия и Туркмения. Несмотря на систематическое многолетнее снижение заболеваемости раком желудка и смертности от него, для многих стран, включая Казахстан, эта патология остается одной из наиболее важных медицинских и социальноэкономических проблем [2].

Смертность от онкологических заболеваний в Казахстане занимает второе место в структуре смертности населения. Ежегодно от рака умирают порядка 17000 человек, из которых 42\% - лица трудоспособного возраста. Среди онкологических заболеваний рак желудка находится на четвертом месте, которое чаще встречается у пожилых людей и примерно вдвое чаще у мужчин, чем у женщин [3].

В Японии рак желудка остается наиболее распространенным видом рака среди мужчинСтандартизованные по возрасту показатели заболеваемости в Японии составляют 69,2 на 100000 мужчин и 28,6 на 100000 женщин. Исследования проведенные в Японии установили, что доля раннего рака желудка в Японии наивысшая и составляет половину всех случаев, тогда как в Европе, США и других странах она не превышает 20\%. Исходя из результатов этих исследований некоторые ученые сделали вывод о том, что рак желудка у японцев является принципиально отличным от рака желудка у европейцев.Однако, дальнейшие исследования проведенные в сфере молекулярной биологии показали, что успехам в улучшении выживаемости Япония обязана массовому скринингу населения, которые проводятся в Японии начиная с 1960 года [4].
По сравнению с женщинами мужчины имеют более высокий риск развития как кардиального (5-кратно) так и некардиального (2кратно) рака желудка. Причины таких различий не ясны, но имеются предположения, что воздействия окружающей среды и профессиональные особенностимогут сыграть свою роль. Например, мужчины исторически чаще курят табачные изделия, хотя повышенные показатели у мужчин, по-видимому, сохраняются даже в тех странах, где мужчины и женщины имеют одинаковыйанамнез курения. Альтернативно, половые различия могут отражать физиологические различия. Эстрогены могут защитить от развития рака желудка. Замедленная менопауза и повышенная фертильность женщин могут снизить риск развития рака желудка, тогда как антиэстрогеновые препараты, например тамоксифен, могут увеличить скорость наступления данного заболевания. Эти гормоны могут обеспечить защиту против рака желудка в течение фертильных лет женщин, но их эффект уменьшается после менопаузы [5].

Похожие заключения сделаны в работах шведских исследователей, которые изучили эффект гормональной заместительной терапией среди 299 женщин с раком пищевода, 313 с раком желудка и 3191 случайно выбранных женщин контрольной группы. Результаты данного исследования показывают уменьшение на 50\% риска аденокарциномы желудка, тогда как,связь между заместительной гормональной терапией и аденокарциномой пищевода не наблюдалась [6].

Таким образом, многие исследования показывают, что рак желудочно-кишечного тракта, в частности верхние желудочно-кишечные аденокарциномы чаще встречается у мужчин. Однако, исследование проведенное в университете Глазго констатирует факт высокого распространения рака желудочно-кишечного тракта зависит не только от анатомического расположения опухоли, а его гистологического типа [7]. 
В результате проведенных исследований во всем мире были установлены основные предраспологающие факторы ускоряющие наступление рака желудка. Так, исследование проведенное в Китае констатирует, что наиболее часто рак желудка встречается среди мужчин курящих и злоупотребляющих алкогольными напитками [8]. Курение табака является широко известным фактором риска развития рака верхней части желудочно-кишечного тракта. Связь между курением и аденокарциномой пищевода показана несколькими исследованиями $[9,10]$.

Преобладание мужчин среди некоторых распространенных видов рака связано с разными темпами курения среди мужчин и женщин, поскольку мужчины курят чаще чем женщины, что установлено в результате многих работ во многих разных географических частях мира. Например, заболеваемость раком легких исторически была выше у мужчин, чем у женщин во всем мире. Тем не менее, поскольку распространенность курения у мужчин и женщин стала более схожей, показатели заболеваемости раком легких у обоих полов также сходятся $[11,12]$.

Результаты крупных когортных исследований показывают сходные показатели заболеваемости раком легких у мужчин и женщин с аналогичной историей курения [13]. Хотя роль курения в развитии верхних желудочнокишечных аденокарцином не такая большая, как роль легких, потенциальная роль курения табака в качестве объяснения преобладания этих опухолей у мужчин также оценивалась. Так, исследование в США установил, что рак желудка одинаково часто встречается как у курящих, так и у некурящих мужчин [14].

Кроме известных факторов риска в литературе имеются изучения рака желудка у мужчин в зависимости от этнической принадлежности. Так, в исследовании проведенном на Гавайях рак желудка регистрировался чаще среди мужчин европеоидной расы чем у темнокожих мужчин и не ассоциировался с мультифокальным гастритом[15]. В другом исследовании, проведенном в Новом Орлеане, показатели заболеваемости раком желудка были в два раза выше среди выходцев из Латинской Америки, чем не испаноязычных белыхмужчин [16].

До 1940-х годов рак желудка был наиболее распространенной причиной смерти от онкологических заболеваний среди мужчин. Снижение смертности от рака желудка в развитых странах началось еще в 1926 году, в частности в
Соединенных Штатах. Данная тенденция, наблюдаемая в последние несколько десятилетий в экономически развитых странах, вероятно, может быть очевидным в регионах, где проводится скрининг рака желудка. Мотивированный высокими показателями заболеваемости и смертности от рака желудка, Япония представила программу массового скрининга в 1960-х годах. Двухуровневые рентгеновские лучи бария были предложены во всей территории Японии к 1975 году, а в последнее время люди прошли скрининг с помощью эндоскопии, концентрации пепсиногена в сыворотке и анти-Н. Pylori. Считается, что использование данных наблюдений, включая когортные исследования, исследования случайконтроль и экологические анализы из разных муниципалитетов с различным уровнем участия в скрининге, привело к снижению смертности от рака желудка в Японии [17].

\section{Conclusion}

Таким образом, несмотря на некоторое снижение заболеваемостирак желудка среди мужчинво всем мире, в том числе и в Казахстане остается чрезвычайно острой проблемой. По определению ВОЗ рак желудка в ранней стадии выявляется всего в $10 \%$ случаев, а снижение показателей заболеваемости раком желудка, как среди мужчин, так и среди женщин, наблюдаемое с 80-х годов прошлого века, объясняется изменением характера питания и качества потребляемых продуктов и внедрением эндоскопических методов исследования, значительно улучшившей диагностику рака и предраковых заболеваний.В Казахстане в 2013 году внедрены скрининговые осмотры на раннее выявление рака желудка в такаих пилотных регионах как, Восточно-Казахстанская область, Западно-Казахстанская область, Кызылординской, Павлодарской областях, городах Астана и Алматы. В 2014 году данные скрининги были внедрены в Атырауской, СевероКазахстанской, Карагандинской, Актюбинской, Костанайской областях.За 2013 год по скринингу рака пищевода и желудка осмотрено более 150 тыс. человек, выявлено 29 случаев рака пищевода (1-2 стадия $-72,4 \%)$ и 66 случаев рака желудка (12 стадии $-72,7 \%)[18]$.

Исходя из этого ранняя диагностика предопухолевых заболеваний и рака желудка, особенно у мужчин, имеет огромное значения для снижения заболеваемости и смертности от рака желудка а также улучшение здоровья мужчин в целом. 


\begin{tabular}{l|lr|ll|ll} 
& ISRA (India) & $=\mathbf{1 . 3 4 4}$ & SIS (USA) & $=\mathbf{0 . 9 1 2}$ & ICV (Poland) & $=\mathbf{6 . 6 3 0}$ \\
Impact Factor: & ISI (Dubai, UAE) $=\mathbf{0 . 8 2 9}$ & PUHЦ (Russia) $=\mathbf{0 . 2 0 7}$ & PIF (India) & $=\mathbf{1 . 9 4 0}$ \\
& GIF (Australia) & $\mathbf{0 . 5 6 4}$ & ESJI (KZ) & $=\mathbf{3 . 8 6 0}$ & IBI (India) & $\mathbf{= 4 . 2 6 0}$ \\
& JIF & $=\mathbf{1 . 5 0 0}$ & SJIF (Morocco) & $\mathbf{2 . 0 3 1}$ & & \\
\hline
\end{tabular}

\section{References:}

1. Nurgaziev K.N., Zhylkaydarova A.Zh., Nurgaliev N.S., Nersesov A.V., Akhmetzhanov O.T., Ishkinin E.I. (2014) Ministerstvo zdravookhraneniya respubliki Kazakhstan natsional'nyy tsentr problem formirovaniya zdorovogo obraza zhizni. Metodicheskie rekomendatsii. Almaty, 2014 g. str-10-13

2. (2002) Zlokachestvennye novoobrazovaniya $v$ Rossii i stranakh SNG v 2000. Statistika zabolevaemosti i smertnosti ot zlokachestvennykh novoobrazovaniy v 2000 godu. Moskva, RONTs im. N.N. Blokhina RAMN. 2002, -s.85-106

3. Orazova G.U., Dosakhanov A.Kh., Bermagambetova G.N., Karp L.L. (2012) ClinicalmedicineofKazakhstan №4 (26), 2012. problemy vyyavlyaemosti zlokachestvennykh novoobrazovaniy zheludka i pishchevoda (PO dannym literatury).g. Astana, Kazakhstan.

4. Parkin DM. (2004) International variation. Oncogene. 2004; 23:6329-6340

5. (2014) Cancer Epidemiol Biomarkers Prev. 2014 May;23(5): 700-13. Gastric cancer: descriptive epidemiology, risk factors, screening, and prevention.Karimi P, Islami F, Anandasabapathy S, Freedman ND, Kamangar F.

6. Lindblad M, García Rodríguez LA, Chandanos E, Lagergren J. (2006) $\mathrm{Br}$ J Cancer. Jan 16;94(1):136-41. Hormone replacement therapy and risks of oesophageal and gastric adenocarcinomas.

7. Derakhshan MH, Liptrot S, Paul J, Brown IL, Morrison D, McColl KE. (2009) Gut. Jan;58(1):16-23. Oesophageal and gastric intestinal-type adenocarcinomas show the same male predominance due to a 17 year delayed development in females.

8. Zhang QL, Zheng W, Li HL, Gao J, Fang J, Gao LF, Liu DK, Shu XO, Xiang YB. (2017) Zhonghua $\mathrm{Yu}$ Fang Yi XueZaZhi. May $6 ; 51(5): 386-392$. The joint effects of major lifestyle factors on stomach cancer risk among Chinese men: a prospective cohort study.
9. Freedman ND, Abnet CC, Leitzmann MF, et al. (2007) Am J Epidemiol. 2007; 165:1424-1433. A prospective study of tobacco, alcohol, and the risk of esophageal and gastric cancer subtypes.

10. Sjödahl K, Lu Y, Nilsen TI, et al. (2007) Int J Cancer. 120:128-32. Smoking and alcohol drinking in relation to risk of gastric cancer: a population-based, prospective cohort study.

11. Jemal A, Travis WD, Tarone RE, Travis L, Devesa SS. (2003) Int J Cancer. 105:101-7. Lung cancer rates convergence in young men and women in the United States: analysis by birth cohort and histologic type.

12. Devesa SS, Bray F, Vizcaino AP, Parkin DM. (2005) Int J Cancer. 117:294-9. International lung cancer trends by histologic type: male:female differences diminishing and adenocarcinoma rates rising.

13. Bain C, Feskanich D, Speizer FE, et al. (2004) J Natl Cancer Inst. 6:826-34. Lung cancer rates in men and women with comparable histories of smoking.

14. Freedman ND, Leitzmann MF, Hollenbeck AR, Schatzkin A, Abnet CC. (2008) Lancet Oncol. 9:649-56. Cigarette smoking and subsequent risk of lung cancer in men and women: analysis of a prospective cohort study.

15. Stemmermann GN, Nomura AM, Kolonel LN, Goodman MT, Wilkens LR. (2002) Cancer. Aug 15;95(4):744-50.Gastric carcinoma: pathology findings in a multiethnic population.

16. Wu X, Chen VW, Andrews PA, Ruiz B, Correa P. (2007) Cancer Causes Control. Aug;18(6):585-93. Incidence of esophageal and gastric cancers among Hispanics, non-Hispanic whites and non-Hispanic blacks in the United States: subsite and histology differences.

17. (2017) Available: https://medictionary.ru/rakzheludka-klassifikaciya-smertnost/ (Accessed: 10.12.2017).

18. (2013)

Available:

https://www.zakon.kz/4603686-v-2013-godu-vkhode-skriningovykh.html 10.12.2017). 